Journal of Teacher Education for Sustainability, vol. 21, no. 1, pp. 115-127, 2019

\title{
EFL Teachers' Cultural Identity Development through Participating in Cultural Negotiation: Probing EFL Students' Perspectives
}

\author{
Hussein Meihami \\ Shiraz University, Shiraz, Iran \\ Ilga Salìte \\ Daugavpils University, Daugavpils, Latvia
}

\begin{abstract}
This study was an attempt to probe the perceptions of the EFL students about the cultural identity development of the EFL teachers who participated in cultural negotiation programs. To that end, the interactionally oriented narratives of four EFL students were collected. The narratives were about the cultural performance of the EFL teachers who participated in the cultural negotiation programs in the EFL classes. The narratives were codified based on the principles of Strauss and Corbin (1998) systematic approach. the findings indicated that the EFL students had positive opinions about how their teachers dealt with cultural issues in the classrooms after participating in cultural negotiation programs. The findings also indicated that the EFL students perceived that the EFL teachers engaged more in cultural discussions, they used more interaction types, they were more motivated to address cultural issues in the classes, and they took into account the emotions of their students in cultural discussions in the classrooms. Moreover, it can be concluded from the findings that cultural negotiation programs have positive effects on the EFL teachers' cultural identity development if the principles of identityas-practice and identity-in-discourse will be followed in the EFL teacher education programs.
\end{abstract}

Keywords: cultural identity, narrative, systemic approach, identity-as-practice.

\section{Introduction}

Language teacher identity finds a well-established arena of research in the last two decades. Hence, it is now very common to see different terminologies related to language teacher identity in journal reports, handbooks, and encyclopedias published in the field of language learning and teaching (Norton \& Toohey, 2011). Moreover, it can be observed that researchers in the field of teacher education in general, and language teacher education in particular, are interested to investigate the relationship among teachers' identity and other attributes such as emotion, motivation, profession, etc. (e.g. 
Day, 2018; Miller, 2009; Richardson \& Watt, 2006). The reason for such a keen interest in doing research to examine different aspects of language teacher identity can be the fact that by understanding language teacher identity and the way to develop it, language teacher educators can understand the way to develop the teaching profession of language teachers (Kumaravadivelu, 2012).

The concept of identity does not develop in vacuum, yet it is a socially constructed attribute which has different angles that lead to various viewpoints when one tries to define it. Preece (2016) defines identity as a socially constructed phenomenon resulted from "the mobility and diversity that has arisen in the social worlds of the physical and digital world due to the processes of globalisation in late modernity" (p. 3). Moreover, Norton (2013) describes identity as the way an individual tries to perceive him/herself in accordance to others. The two definitions are implicitly mentioning the concept of negotiating self. Heller (1987) declares that negotiating self is all the potentialities which an individual has in order to disseminate his/her beliefs, assumptions, and values in a society and accept others' beliefs, assumptions, and values. The context of English language teaching and learning is called to be a cosmopolitan one (Stanton, 2006); meaning that it is a community with different members which the cultural identity development and understanding of each of them is crucial to the final act of teaching and learning. In this regard, the cultural aspects of identity will be considered as very important.

Cultural identity is defined as "an umbrella construct to encompass, or subsume, related identity groups such as nationality, race, ethnicity, age, gender, socioeconomic status, regional identity, ethnolinguistic identity, political affiliation, and (dis)ability" (Chen \& Lin, 2016, p. 2). Cultural identity may be negotiable (Yagi \& Kleinberg, 2011) or not depending on various factors. That said, the cultural identity of language teachers can be addressed if they participate in cultural negotiation programs in which they negotiate on different cultural concepts which are associated to cultural identity. Negotiation in this sense can be described as a mean of "getting thing accomplished" (Strauss, 1978, p. 11). In the context of EFL teaching, accomplishing the act of teaching and learning by teachers and students, respectively, is the point in which negotiation of cultural identity can be of advantages (Rashidi \& Meihami, 2019). It is without saying that the cultural identity development of EFL teachers can be perceived by the EFL students in different ways. Moreover, the cultural identity development of EFL teachers may have effect on teaching profession and, finally, on EFL students learning. That said, in the current study, the researcher investigated EFL students' perceptions on the cultural identity development of EFL teachers who participated in the cultural negotiation programs. As a whole, the aim of this study was to track down the perceptions of EFL students about cultural identity development of EFL teachers to examine the cultural identity development of the EFL teachers through the lens of the EFL teachers.

\section{Cultural Identity Theories}

The fundamental underpinnings of cultural identity can be summarized in several theories. Addressing these theories chronologically, the first theory is cultural identity negotiation theory introduced by Collier and Thomas (1998). This theory is conceived to be an interpretive inquiry to cultural identity. According to this theory of cultural identity, negotiation of cultural identity helps the individuals to specify their current positions compared to others in order to share their cultural identity. Collier and Thomas 
(1988) state that there are five processes which should be addressed when this theory is focused, including scope, salience, intensity, avowal, and ascription. Meihami (2019, p. 18) states that by going through different processes of cultural identity negotiation theory "interactions in different contexts, during different time intervals, and with different audiences bring different cultural identifications which are influential in negotiation of cultural identity."

In 2002, Jackson proposed cultural contract theory in which it states "intercultural relationship may or may not be coordinated, depending upon the dynamics involved, such as power, boundaries, cultural loyalty, group identification, and maturity" (Jackson, 2002, p. 361). In this theory of cultural identity, an individual can negotiate his/her cultural identity based on involving in three contracts including ready-to-sign contract, quasi-completed contract, and co-created contract. Going through the three contracts is similar to a continuum in its early stage the individual does not prefer to shift his/her cultural identity, in the middle stage he/she likes to reconstruct his/her cultural identity provided that his/her beliefs, values and assumptions will be respected, and in the ending stage the individuals share their cultural identity with others' cultural identity and construct new type of cultural identity and accept it.

Identity management theory (Imahori \& Cupach, 2005), as a theory of cultural identity, assumes identity as the building block of intercultural communication. The main assumption of identity management theory is that individuals from different cultures can negotiate their cultural identities if three phases of identity management theory including trial, enmeshment, renegotiation, will be accomplished. In the first phase, trial, the individuals find it important to communicate with others based on sharing their cultural identity. In the second phased, enmeshment, individuals' first symbolic convergence will be held. If the first two phases will go right, then, the third phase which is renegotiation will be followed. In the renegotiation phase, and individual negotiates his/her cultural identity with others.

Another cultural identity theory which is proposed by Stella Ting-Toomey (2005) is identity negotiation theory. The main concern of this theory is that sense of satisfaction for an individual will specify whether or not, to negotiate his/her cultural identity with others. In this regard, it should be stated that the first perceptions of an individual with a community which he/she wants to share his/her cultural identity is very important. Five main concepts are regarded as the themes of identity negotiation theory including identity security and identity vulnerability, identity inclusion and identity differentiation, identity predictability and identity unpredictability, identity connection and identity autonomy, and identity consistency and identity change. It is worth mentioning that these theme are context-laden; meaning that in each specific context, one or more than one of them are activated. Moreover, in this theory, the importance of ethnic identity and its relationship with an individual's cultural identity is well taken into account.

\section{EFL Teacher Cultural Identity}

Research on EFL teacher cultural identity is in its infancy. Teaching and learning in the EFL context are not without conflicts for teachers and students. because they have their own cultural values, assumptions, beliefs, and, ultimately, cultural identity; causing "tensions and struggles ... common themes in the construction of language teachers' bior multi-cultural identities” (Martel \& Wang, 2015, p. 239). However, it should be noted 
that if the conflicts and tensions will be negotiated appropriately, a secondary cultural identity can be achieved by the EFL teachers and learners which is related to the EFL context they have already participated (Fichtner \& Chapman, 2011).

It is true that many of the discussions and debates made in the EFL contexts are based on members', either teachers or students, cultural identities; meaning that their social and cultural values may be the main topic of discussions and debates in the classroom. Accordingly, "problems may arise when teachers' or students' identities and beliefs related to gender roles, nationality, ethnicity... or local culture" are discussed and debated in the classroom (Duff \& Uchida, 1997, p. 452). Furthermore, since English, as an international language, is not a culturally neutral language, English teaching and learning may have impact on cultural identity construction of teachers and learners. In its own place, it will lead to the importance of administrating cultural negotiation programs in the EFL teacher education programs to help EFL teachers be more competent in managing their cultural performance in their classrooms.

There is a paucity of empirical study about EFL teachers' cultural identity development. Moreover, to date, there is no study examining the perceptions of EFL students about the cultural identity development of their teachers who participate in cultural negotiation programs. Fichtner and Chapman (2011) conducted a study to see how foreign language teachers affiliate themselves with more than one culture. They found that, foreign language teachers embrace their own culture but they do not embody "the other" culture. Moreover, Rashidi and Meihami (2017) went through the studentteachers' narratives to investigate the role of negotiation about cultural issues on their cultural identity development. The findings of their study indicated that the studentteachers' cultural identity developed after their participation in cultural negotiations; in that, they changed their views about the cultural differences and the way they could make use of them in their teaching.

\section{Method}

This study was aimed to investigate the EFL students' perceptions about the cultural identity development of EFL teachers participating in cultural negotiation programs. To that end, the narratives authored by the EFL students whose teachers were in a cultural negotiation programs during the conduction of this research were collected. It is worth mentioning that these EFL teachers were participating in a cultural negotiation program aimed to develop their cultural literacy about cultural variations and how to deal with cultural variations in their classrooms. The setting of doing this study was an Iranian EFL context in which the EFL students were learning English as a foreign language.

\section{Participants}

Four EFL students participated in the current study to help the researcher address the cultural identity development of the EFL teachers in the classrooms. These students were the English students of the EFL teachers who were participating in the cultural negotiation program. Three of these students were male and one was female. Their proficiency level, as stated by their institute officials, was upper intermediate. The students were selected based on convenience and their interest to participate in the study. Their pseudonyms were Mahmoud, Sina, Leyla, and Karim. It should be stated that the inter- 
actions with all of the students were not face-to-face, but through different social medias. However, with some of them the researcher had sessions to consult different issues. The students were asked to write down their interactional narratives.

\section{EFL Students' Narratives}

There are two main types of approaches to collect and analyze the narratives, namely, biographical and interactionally oriented approaches (De Fina, 2015). The difference lies on how the life stories and interactions are approached as the source of data. The biographical oriented approach to narrative analysis assumes that "identity building has as its objective the production of a coherent self, and that the ability to create that coherence afforded by narrative has itself a positive effect on selfidentity" (Freeman, 2015; as cited De Fina, 2015, p. 352); asking for life story writing by individuals at one point of time. However, the interactionally oriented approach to narrative analysis points out the importance of interactions among different stakeholders of the narratives. In the interacttionally oriented approach to narrative analysis social interactions are regarded as important.

Due to the nature of the study, the researcher asked the students to write interactional narratives. It is so because the researchers need to see the perspectives of the student during different time intervals. One more reason to ask students to write interactional narratives was that the researcher wanted to track down the cultural identity development of the EFL teachers participating in the cultural negotiation programs during different time intervals and through the narratives written by the EFL students who participated in the classes of those teachers. Given that, the EFL students were asked to write down their narratives during three time intervals, at start of EFL teachers cultural negotiation program, at the middle of it, and at the end of it. During these three time intervals, the EFL students had different classroom interactions which led them to write their narratives interactively. Moreover, by going through the narrative written during these intervals, the researcher could draw the students' perspectives about EFL teachers' cultural identity development. It should be noted that to eliminate the effect of language proficiency on writing narratives (Bilgen \& Richards, 2015), the EFL students were asked to follow their preferences in selecting either English or Persian language. However, it should be noted that those narratives which were written in Persian were translated by the researcher into English and, then, another English translator tried to translate them to Persian to examine the agreement. By so doing, the issue of narrative analysis of Persian written narratives would be solved.

\section{Data Analysis Procedure}

To analyze the narratives written by the EFL students, the researcher used systematic approach proposed by Strauss and Corbin (1998) which is related to grounded theory (Ary et al., 2014). There are three coding levels in systematic approach: open coding, axial coding, and selective coding. The researcher started to analyze the narratives by open coding. In this level of coding the major or core categories were specified. The next level was axial coding in which the categories were broken into subcategories and sub-themes. Finally, in the selective coding, the researcher developed propositions and 
hypotheses. To conduct correct narrative analysis MAXQDA 10 was used. Table 1 shows an example of the analysis of part of the narrative authored by an EFL students:

Table 1

An Example of Narrative Analysis through Systematic Approach

\begin{tabular}{|c|c|c|c|}
\hline Example 1 & Open Coding & Axil Coding & Selective Coding \\
\hline $\begin{array}{l}\text {... our teacher talked about the cultural } \\
\text { issues in the textbooks and the related } \\
\text { outside concepts from the first sessions } \\
\text { but it was in the middle of the semester } \\
\text { that some of the students, one of them } \\
\text { was me, participated in the discussions.. }\end{array}$ & $\begin{array}{l}\text { - Addressing } \\
\text { cultural } \\
\text { issues in the } \\
\text { classroom }\end{array}$ & $\begin{array}{l}\text { - Cultural } \\
\text { engagement } \\
\text { of the EFL } \\
\text { teachers }\end{array}$ & $\begin{array}{l}\text { - Student- } \\
\text { teacher cultural } \\
\text { negotiation }\end{array}$ \\
\hline
\end{tabular}

As can be seen in Table 1, through examining the EFL students' narratives, one can understand that the cultural identity of the EFL teachers developed since they tried to negotiate more on cultural issues in their classrooms.

To address the rigor of the study for the matter of correct narrative analysis, the researcher used member checking to be assure about the credibility of the narrative analysis, in which the researcher consulted parts of the narratives that were vague with the participants. Moreover, the transferability of the narratives was addressed through cross-case participants in that the students were from different institutes and the students of different EFL teachers participating in the cultural negotiation programs. Furthermore, the dependability of data analysis was done by asking another coder to go through the $50 \%$ of the narratives to analyze them. The findings indicated that the agreement between the two coders was satisfactory.

\section{Findings and Discussion}

The EFL students' narratives were analyzed to see what their perspectives were about the cultural identity development of their teachers. Their narratives showed several main themes which are discussed in the following section.

\section{Cultural Engagement}

The analysis of the students' narratives indicated that they believed in the development of EFL teachers' cultural engagement in the classrooms while these teachers participated in cultural negotiation programs. Leyla's and Karim's narratives indicated that these teachers tried to start addressing cultural issues from the first sessions but they were not that successful since their students did not accept discussions. However, based on the analysis of the narratives by the EFL students, they could do so and address cultural issues sooner than the middle of the semester. Excerpts 1 and 2 are parts of excerpts authored by Leyla and Karim, respectively.

\section{Excerpt \# 1}

... our teacher talked about the cultural issues in the textbooks and the related outside concepts from the first sessions but it was in the middle of the semester that some of the students, one of them was me, participated in the discussions ... 


\section{Excerpt \# 2}

In the fourth or fifth session, I had a discussion on [speech act] of refusal in cultures ... the teacher had his own idea and was firmly stating it ... these discussions continued till the final sessions ... the teacher was less firm and more accepting others opinions...

The two excerpts ( 1 and 2 ) show that the EFL teachers tried to use cultural issues in a way to continue the process of English language teaching. Although they were rigid on their ideas at the start of the semester, at the end and when they participated in negotiation sessions they were less rigid. It means that these teachers did not position themselves as rejecters of others cultural ideas, but they tolerated their ideas and discussed them. The development in cultural engagement of the EFL teachers in their classrooms with their EFL learners show the development of their cultural identity (Rashidi \& Meihami, 2017). Based on the findings, it can be stated that EFL teachers' participation in the cultural negotiation programs led to the emphasis of identity-as-practice in their classes (Kanno \& Stuart, 2011; Wenger, 1998). Thus, the EFL teachers' cultural engagement in their classes developed; which led them to become aware about cultural variations in the classes and to engage in cultural discussions with more openness. Consequently, it can be stated that through participating in the cultural identity negotiation programs, the EFL teachers will be aware about the cultural variations and how to deal with them; and in their classes, they will engage in cultural discussions in that they learn to become teachers who are prudent about their learners' cultural affairs.

\section{Interaction Types}

EFL students' narrative analysis showed that they believed that the EFL teachers who participated in the cultural negotiation programs used different types of interactions to address the cultural discussions in their classrooms. The results of narrative analysis indicated that EFL teachers used teacher-student interaction type in the first sessions, then, they changed it to student-student interaction, and, finally, to teacher-studentstudent interactions. Excerpts 3 and 4 authored by Sina and Mahmoud, respectively.

\section{Excerpt \# 3}

... as I stated, we had cultural issue discussions from the first sessions but at first they were between teacher and the students. Later on, the discussions were among the students....

\section{Excerpt \# 4}

Once, [at the final sessions of the semester] when the content of the textbook was about the way we call each other, I remember there was a discussion in which the teacher helped all the students to talk to each other and discuss the issue...

Excerpts 3 and 4 show that the EFL teachers used all interaction types to address cultural issues happened in their classes for the purpose of helping EFL students to use English to discuss these issues. The point is none of the students mentioned in their narratives that the EFL teachers used Persian for discussing the issues; showing that the 
EFL teachers were competent in addressing cultural issues through English language. The teachers used the context of their classrooms as a discourse arena to practice cultural negotiation. Identity-in-discourse (Kanno \& Stuart, 2011) which is the construction of identity discursively can be tracked down in the narratives authored by EFL students. Consequently, through establishing different discourses, the teachers intended to discuss different cultural concepts. The EFL students' narratives showed that from the early stages to the ending of the program, the EFL teachers' use of identity-in-discourse developed; meaning that the cultural negotiation programs which the EFL teachers have already participated had positive effects on their cultural identity development.

\section{Teacher Motivation}

The analysis of EFL students' narratives indicated that the motivation of EFL teachers who participated in the cultural negotiation programs increased regarding the cultural performances and discussions in the classrooms. Excerpts 5 and 6 are parts of narratives authored by Sina and Leyla, respectively.

Excerpt \# 5

... the thing was that in the first sessions of our classes, our teacher did not that much interested to talk about different cultural issues ... several times in the final sessions I heard from our teacher that he stated "OK, everybody, Let's talk about the cultural points of this issue” ...

\section{Excerpt \# 6}

... from the middle of the program onward, I see new MOTIVATION in our teacher to discuss cultural issues regarding our classroom discussions ...

As can be seen from parts of the narratives authored by Sina and Leyla, the EFL students believed that the motivation of their EFL teachers flourished to consider cultural discussions in the classrooms. Teacher motivation in general, and EFL teacher motivation in particular, is a multidimensional, complex, and responsive concept (Butler, 2014; Richardson \& Watt, 2006). That said, it is not an easy task for teacher educators to address and develop this issue in teacher education programs. Richardson and Watt (2018, p. 42) state that

Personal and social identities are responsive to different contextual factors and influence what teachers are motivated to do, the action they will take to achieve their goals, how well they will "fit" within the work culture of the school, their work satisfaction and whether the resources available to them support or undermine their commitment, persisitence and identity as a teacher.

Accordingly, it can be argued that the motivation of the EFL teachers who participated in the cultural negotiation programs changed; leading to their cultural identity development and change in their cultural performances. Attending in a context in which negotiation about various cultural concepts happened led the EFL teachers to be motivated to achieved their teaching goals. Hence, the development in the motivation of these teachers led them to practice more on addressing cultural issues in their classes. 


\section{Teacher Emotion}

Finally, the EFL students mentioned development in their teacher emotion in their narratives. Parts of the narratives authored by Mahmoud and Karin are shown in excerpts 7 and 8.

\section{Excerpt \# 7}

... our teacher tried to take into account our feeling when there was a discussion about cultural issues [at the middle of program onward] ... when he thought that one of the students might get annoyed from the way he discussed the cultural concept, he tried to appease [settle down] the emotional issues ...

\section{Excerpt \# 8}

I think the more our English program reaches its termination, the more our teacher tried to consider the students' discussions about cultural issues ... our teacher tried to harm nobody in the discussions...

There is a direct relationship between teacher emotion and teacher identity since by understanding the emotional messages of the class, the teachers make decision how to arrange their teaching (Day, 2018). Moreover, Wróbel (2013) believes that teachers are "emotional labors" since,

it seems obvious that emotions play an important role in the workplace. This can be true especially in the case of teachers whose role is not only to teach, but also to establish and maintain a learning-friendly environment. In practice, it may mean showing enthusiasm while conducting classes, reacting with empathy to pupils' worries and needs, hiding fatigue and annoyance or displaying positive emotions even when pupils are being difficult and rude. Teachers have to educate and, at the same time, manage their own emotions to meet the expectations associated with their profession ... In other words, they perform emotional labor (p. 581).

It can be stated that through participating in cultural negotiation programs, the EFL teachers' cultural-professional identity developed. It is so because by using the notions they learnt in the negotiation programs, and by perceiving the cultural status of their classes, they tried to address cultural issues in their classes. In so doing, they tried to take into account the emotions of their students and select their teaching methodology by considering the emotions of their students. Owing to this, the classes were changed to a learning-friendly ones in which cultural issues could be discussed and debated. Moreover, by understanding the emotional messages of the classroom, the EFL teachers conduct "deep acting" (Grandey \& Gabriel, 2015) in which they do their best to consider the emotions of their students in their teaching methods.

\section{Conclusions and Implications}

This study was an attempt to probe perception of the EFL students about the cultural identity development of the EFL teachers who participated in cultural negotiation programs. The findings of this study indicated that the EFL students had positive opinions about 
how their teachers dealt with cultural issues after participating in cultural negotiation programs. The findings also indicated that the EFL students perceived that the EFL teachers engaged more in cultural discussions, they used more interaction types, they were more motived to address cultural issues in the classes, and they took into account the emotions of their students in cultural discussions in the classrooms. Thus, the findings of this study is in line with Rashidi and Meihami (2017), Yazan (2018), and Yazan and Peercy (2018) in that the importance of negotiation in identity development of language teachers is acknowledged.

It can be concluded from the findings of the current study that one new aspect of EFL teachers' professional identity to be called cultural-professional identity was addressed through their participation in the cultural negotiation programs. The points which were been stated in the narratives of the EFL students including EFL teachers' cultural engagement, their use of different interaction types, their motivation development and their consideration of EFL students' emotion showed that the EFL teachers' professional identity developed that since this identity was about cultural performances in the classrooms, it can be regarded as cultural-professional identity. The development in cultural identity of the EFL teachers can be obtained through professional negotiation on cultural issues which in its own respect will lead to cultural-professional identity.

Through the findings obtained in this study, one can assume that the cultural negotiation programs which the EFL teachers participated had impact on their instructional identity, too. As an indispensable part of overall identity, the instructional identity is related to the all the contents and methods, reflections which a teacher does to act as a teacher (Pennington, 2015). The EFL teachers obtained cultural knowledge and the methods and approaches to make use of them in the classrooms by participating in the cultural negotiation programs. Consequently, it can be concluded that cultural negotiation programs can be facilitative to develop instructional identity of the EFL teachers, as well as, their professional, cultural, and cultural-professional identity.

One point which should be considered as important and future researchers may address is a context for practicing what is instructed in the cultural negotiation programs to the EFL teachers. In this study, since the EFL teachers could practice, simultaneously, the knowledge they accrued in the negotiation sessions in their classes, they could take the most benefit from it. It is related to identity-as-practice (Kanno \& Stuart, 2011) in which the contexts of practicing identity related issues help the individuals to develop their identity through practicing the related factors. Furthermore, if the EFL teachers have a context of practicing their obtained knowledge, they will find arena to practice different discourses. This is in association to identity-in-discourse (Kanno \& Stuart, 2011) which is about the differences which exist in in different discourses and lead to different identity practices. EFL teacher educators should prepare a context of practice for the EFL teachers in the pre-in service programs to help them practice what they have already obtained in the cultural negotiation programs.

As it was stated earlier, development of teacher motivation is not an easy task. However, the findings of the current study indicated that through participating in cultural negotiation programs, the EFL teachers' motivation to run cultural discussions and to address cultural issues in the classrooms developed. It can be suggested to the EFL teacher educators to change their perspectives about solely theoretical discussions to the negotiated programs. While the former just address the pure knowledge about different issues, 
the latter tries to find an agreement in the way to apply the knowledge about different issues. When the teachers see their ability not only in the theoretical aspects but also in how to apply them in their classes, they will become motivate about their teaching profession.

\section{References}

Ary, D., Jacobs, L. C., Sorensen, C. K., \& Walker, D. (2014). Introduction to research in education. (9 $9^{\text {th }}$ edition). Cengage Learning.

Bilgen, F. E., \& Richards, K. (2014). Identity negotiations of TEFL teachers during a time of uncertainty and redundancy. In Y. L. Cheung, S. B. Said, \& K. Park (Eds.), Advances and current trends in language teacher identity research (pp. 83-95). New York: Routledge.

Butler, R. (2014). What teachers want to achieve and why it matters: An achievement goal approach to teacher motivation. In P. W. Richardson, S. A. Karabenick, \& H. M. G. Watt (Eds.), Teacher motivation: Theory and practice (pp. 20-35). New York: Routledge.

Chen, Y., \& Lin, H. (2016, July). Cultural identities. Oxford Research Encyclopedia, Communication. Retrieved 6 September, 2018, from http://communication.oxfordre. com/view/10.1093/acrefore/9780190228613.001.0001/acrefore-9780190228613$e-20$.

Collier, M. J., \& Thomas, M. (1988). Identity in intercultural communication: An interpretive perspective. In Y. Y. Kim \& W. B. Gudykunst (Eds.), Theories of intercultural communication, International and Intercultural Communication Annual (Vol. 12, pp. 99-120). Newbury Park, CA: SAGE.

Day, C. (2018). Professional identity matters: Agency, emotions, and resilience. In P. A. Schutz, J. Hong, \& D. C. Francis (Eds.), Research on teacher identity (pp. 6170). Cham: Springer.

De Fina, A. (2015). Narratives and identity. In A. De Fina \& A. Georgakopoulou (Eds.), The handbook of narrative analysis (pp. 351-368). New York: John Wiley \& Sons.

Duff, P. A., \& Uchida, Y. (1997). The negotiation of teachers' sociocultural identities and practices in postsecondary EFL classrooms. TESOL Quarterly, 31(3), 451486.

Fichtner, F., \& Chapman, K. (2011). The cultural identities of foreign language teachers. L2 Journal, 3(1), 116-140.

Grandey, A. A., \& Gabriel, A. S. (2015). Emotional labor at a crossroads: Where do we go from here? Annual Review of Organizational Psychology and Organizational Behavior, 2(1), 323-349.

Heller, M. (1987). The role of language in the formation of ethnic identity. In J. Phinney and M. Rotheram (Eds). Children's ethnic socialization (pp. 180-200). Newbury Park, CA: Sage.

Imahori, T. T., \& Cupach, W. R. (2005). Identity management theory: Facework in intercultural relationships. In W. B. Gudykunst (Ed.), Theorizing about intercultural communication (pp. 195-210). Thousand Oaks, CA: SAGE.

Johnson, K. (2005). Expertise in second language learning and teaching. New York: Palgrave Macmillan. 
Kanno, Y., \& Stuart, C. (2011). Learning to become a second language teacher: Identities in practice. The Modern Language Journal, 95(2), 236-252.

Kumaravadivelu, B. (2012). Language teacher education for a global society: A modular model for knowing, analyzing, recognizing, doing, and seeing. Abingdon: Routledge.

Martel, J., \& Wang, A. (2015). Language teacher identity. In M. Bigelow \& J. EnnserKananen (Eds.), The Routledge handbook of educational linguistics (pp. 289-300). New York: Routledge.

Meihami, H. (2019). The role of negotiation in developing ESP and EGP teachers' cultural identity. An Unpublished PhD Dissertation.

Miller, J. (2009). Teacher identity. In A. Burns and J. C. Richards (Eds.), The Cambridge guide to second language teacher education (pp. 172-181). New York: Cambridge University Press.

Norton, B. (2013). Identity and language learning: Extending the conversation. London: Multilingual matters.

Norton, B., \& Toohey, K. (2011). Identity, language learning, and social change. Language Teaching, 44(4), 412-446.

Pennington, M. C. (2015). Teacher identity in TESOL: A frames perspective. In Advances and current trends in language teacher identity research (pp. 38-52). New York: Routledge.

Preece, S. (2016). The Routledge handbook of language and identity. New York: Routledge.

Rashidi, N., \& Meihami, H. (2017). Addressing cultural identity through negotiation: Analysis of student-teacher-authored narratives. Journal of Teacher Education for Sustainability, 19(2), 21-35.

Rashidi, N., \& Meihami, H. (2019). The role of negotiation about cultural issues on the ESP teachers' cultural identity development: A narrative inquiry. Xlinguae, 12(2), 111-129.

Richardson, P. W., \& Watt, H. M. (2018). Teacher professional identity and career motivation: A lifespan perspective. In P. A. Schutz, J. Hong, \& D. C. Francis (Eds.), Research on teacher identity (pp. 37-48). Cham: Springer.

Richardson, P. W., \& Watt, H. M. G. (2006). Who chooses teaching and why? Profling characteristics and motivations across three Australian Universities. Asia-Pacific Journal of Teacher Education, 34(1), 27-56.

Stanton, D. C. (2006). Presidential address 2005: On rooted cosmopolitanism. PMLA, 121(3), 627-640.

Strauss, A. L. (1978). Negotiations: Varieties, contexts, processes, and social order. San Francisco: Jossey-Bass.

Strauss, A., \& Corbin, J. (1998). Basics of qualitative research. Thousand Oaks, CA: SAGE.

Ting-Toomey, S. (2005). Identity negotiation theory: Crossing cultural boundaries. In W. Gudykunst (Ed.), Theorizing about intercultural communication (pp. 211-233). Thousand Oaks, CA: SAGE.

Wenger, E. (1998). Communities of practice: Learning, meaning, and identity. Cambridge University Press.

Wróbel, M. (2013). Can empathy lead to emotional exhaustion in teachers? The mediating role of emotional labor. International Journal of Occupational Medicine and Environmental Health, 26(4), 581-592. 
Yagi, N., \& Kleinberg, J. (2011). Boundary work: An interpretive ethnographic perspective on negotiating and leveraging cross-cultural identity. Journal of International Business Studies, 42(5), 629-653.

Yazan, B. (2018). Toward identity-oriented teacher education: Critical autoethnographic narrative. TESOL Journal, e00388, 1-15.

Yazan, B., \& Peercy, M. M. (2018). Pedagogically speaking, I'm doing the right things: Three preservice ESOL teachers' identity formation. Teacher Learning and Professional Development, 3(1), 1-18.

Correspondence concerning this paper should be addressed to Hussein Meihami, PhD in Applied Linguistics, Department of Foreign Languages and Linguistics, Shiraz University, 71946-84695, Shiraz, Iran. Email: hussein.meihami@yahoo.com 